\title{
Excimer laser nanostructuring of nickel thin films for the catalytic growth of carbon nanotubes
}

\author{
S. J. Henley, ${ }^{\text {a) }}$ C. H. P. Poa, A. A. D. T. Adikaari, C. E. Giusca, J. D. Carey, \\ and S. R. P. Silva \\ Advanced Technology Institute, School of Electronics and Physical Sciences, University of Surrey, \\ Guildford, GU2 7XH, United Kingdom
}

(Received 9 February 2004; accepted 23 March 2004; published online 5 May 2004)

\begin{abstract}
Pulse laser ablation and subsequent laser nanostructuring at room temperature has been employed to produce nanostructured $\mathrm{Ni}$ on $\mathrm{SiO}_{2} / \mathrm{Si}$ substrates for catalytic growth of carbon nanotubes. The resultant nanostructured surface is seen to consist of nanometer sized hemispherical droplets whose mean diameter is controlled by the initial metal thickness, which in turn is readily controlled by the number of laser pulses. Vertically aligned multiwall carbon nanotube mats were then grown using conventional plasma enhanced chemical vapor deposition. We show that within a single processing technique it is possible to produce the initial metal-on-oxide thin film to a chosen thickness but also to be able to alter the morphology of the film to desired specifications at low macroscopic temperatures using the laser parameters. The influence of the underlying oxide is also explored to explain the mechanism of nanostructuring of the Ni catalyst. (C) 2004 American Institute of Physics. [DOI: 10.1063/1.1751226]
\end{abstract}

Since the discovery of single and multiwall carbon nanotubes $(\mathrm{CNTs})^{1,2}$ there has been intense academic and commercial interest in these fascinating structures. This interest is mainly due to the many and varied potential applications for CNTs including low threshold field emitters ${ }^{3,4}$ for display technologies, nano-scale circuitry ${ }^{5}$ and hydrogen storage. ${ }^{6}$ CNTs have been grown by a variety of different methods including laser ablation, ${ }^{7}$ arc discharge ${ }^{8}$ and more recently, thermal- and plasma-enhanced chemical vapor deposition (PECVD). ${ }^{9,10}$ There has been significant effort focused on understanding the growth mechanisms of CNTs, including the study of how the size and structure of the catalyst particles (typically $\mathrm{Ni}, \mathrm{Fe}$, or $\mathrm{Co}$ ) affect the growth. ${ }^{9-13}$ Many different techniques are used for the preparation of suitable substrates. ${ }^{12,14,15}$ To date the formation of suitable catalyst substrates for CNT growth is accomplished by thermal annealing of thin films deposited by magnetron sputtering ${ }^{12}$ or thermal evaporation. ${ }^{13}$ The latter study involving nanostructuring of $\mathrm{Ni}$ on oxide films at temperatures below $500^{\circ} \mathrm{C}$. In this letter we introduce a method of producing discrete catalyst particles using a combination of pulsed laser ablation $(\mathrm{PLA})^{16}$ and laser nanostructuring (LN). By controlling the laser parameters, such as number of pulses and fluence, we are readily able to control the morphology of the nanostructured Ni films within one process technology. Since only the surface region is exposed to high (local) temperatures during nanostructuring, the macroscopic temperature is not raised significantly, thereby allowing the use of plastic or organic substrates. ${ }^{17}$ This is clearly is more advantageous than requiring one growth method (magnetron sputtering or thermal evaporation) followed by conventional high temperature annealing.

Ni thin films were deposited by PLA of a $99.9 \%$ pure Ni

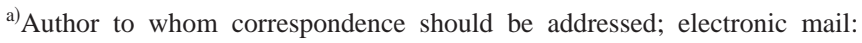
s.henley@eim.surrey.ac.uk
}

target. A Lambda-Physik LPX 200 excimer laser operating at $248 \mathrm{~nm}$ was used for the ablation. The growth chamber was evacuated using a turbo pump to $9 \times 10^{-8}$ Torr. The substrates used were $\mathrm{SiO}_{2} / \mathrm{Si}$ with different values of oxide thickness 235 and $320 \mathrm{~nm}$ of thermal oxide and one with only the native oxide coating. The target to substrate distance was $6 \mathrm{~cm}$ for all depositions. Thin films were grown using 10, 50, 200, 750, 1000, 1500, and 2000 laser shots at laser pulse energy of $100 \mathrm{~mJ}$, focused onto a rotating target, producing a fluence of $\sim 10 \mathrm{~J} \mathrm{~cm}^{-2}$. The initial growth, final smoothness and thickness of the Ni films were investigated in ambient using a Digital Instruments Nanoscope IIIa atomic force microscope (AFM) operating in tapping mode.

The thin films were LN using the same excimer laser as employed for the deposition, by diverting the optical path and passing it through a homogenizer. The films were transferred to a separate vacuum stage (typical working pressure $10^{-4}$ Torr) where the whole sample could be nanostructured by translating the stage. Typical translation rate was $1 \mathrm{~mm} / \mathrm{s}$ with a laser repetition rate of $10 \mathrm{~Hz}$. Postexposure the structure of the films was investigated in a Hitachi S4000 field emission gun scanning electron microscope (SEM).

The initial stages of growth of the Ni films were investigated in the AFM by depositing $\mathrm{Ni}$ onto the $320 \mathrm{~nm}$ $\mathrm{SiO}_{2} / \mathrm{Si}$ substrates. After ten laser shots at a fluence of $10 \mathrm{~J} / \mathrm{cm}^{2}$ the Ni had not formed a continuous film, but consisted of islands. After around 200 shots the islands had coalesced and by 1000 shots a smooth film with a root mean square roughness of $<1 \mathrm{~nm}$ was produced. By masking a section of the substrate prior to deposition, it was possible to measure the Ni film thickness by scanning the AFM over the step produced. Seven hundred and fifty laser shots produced a film $6.5 \pm 0.9$-nm-thick and 1500 shots resulted in a thickness of $8.2 \pm 0.9 \mathrm{~nm}$. The predicted offset for zero laser shots is a consequence of the initial island growth.

After growth the films with 750, 1000, 1500, and 2000 


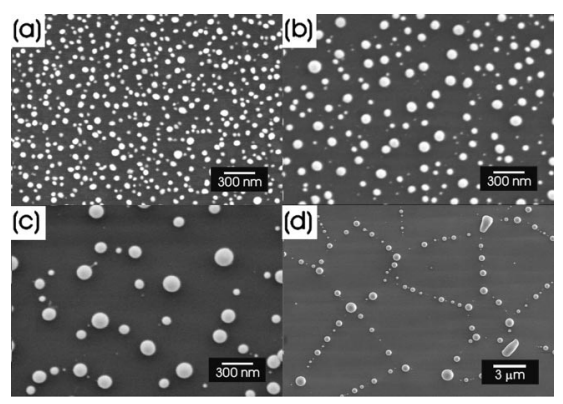

FIG. 1. SEM images of LN Ni films with different thicknesses: (a) 6.5-nm thick film, (b) $8.2 \mathrm{~nm}$, (c) $11.5 \mathrm{~nm}$, and (d) $15 \mathrm{~nm}$. Note the different scale bar on image $(d)$.

laser shots on the different substrates were $\mathrm{LN}$ at a range of laser fluences from 100 to $300 \mathrm{~mJ} / \mathrm{cm}^{2}$. Figure 1 shows SEM images of a selection of the LN films, with different initial Ni thicknesses, grown on $320 \mathrm{~nm} \mathrm{SiO}_{2} / \mathrm{Si}$ substrates. After nanostructuring, the $\mathrm{Ni}$ film was observed to break up into discrete nanometer-scale hemispherical islands. The fluence required to achieve this breakup appeared to be a function of the initial film thickness and the thickness of the oxide layer on the substrate. At lower fluences the films were observed to perforate, but the break up into discrete droplets was incomplete. Above $\sim 280 \mathrm{~mJ} / \mathrm{cm}^{2}$ significant ablation of the $\mathrm{Ni}$ was observed. At intermediate fluences the $\mathrm{Ni}$ island size was unaffected by the laser fluence and the substrates used. The fluence required to nanostructure the films grown on the thinner $(235 \mathrm{~nm})$ thermal $\mathrm{SiO}_{2}$ substrates was higher than for the corresponding $\mathrm{Ni}$ film on the thicker $\mathrm{SiO}_{2}$ layers. On the $\mathrm{Si}$ substrates with only the native oxide layer, no nanostructuring was observed, as it appeared that the fluence required was higher than the ablation threshold of the film. This is most likely due to the higher thermal conductivity of $\mathrm{Si}$ $\left(150 \mathrm{~W} \mathrm{~m}^{-1} \mathrm{~K}^{-1}\right.$ at $25^{\circ} \mathrm{C}$ ) in comparison to that of $\mathrm{SiO}_{2}$ $\left(1.34 \mathrm{~W} \mathrm{~m}^{-1} \mathrm{~K}^{-1}\right){ }^{18}$ Figure 1 (a) shows a 6.5 -nm-thick film $\mathrm{LN}$ at $200 \mathrm{~mJ} / \mathrm{cm}^{2}$, (b) a 8.2-nm-thick film $\mathrm{LN}$ at $160 \mathrm{~mJ} / \mathrm{cm}^{2}$, (c) a $11.5-\mathrm{nm}$-thick film LN at $140 \mathrm{~mJ} / \mathrm{cm}^{2}$ and (d) a 15-nm-thick film $\mathrm{LN}$ at $220 \mathrm{~mJ} / \mathrm{cm}^{2}$. It should be noted that the image in Fig. 1(d) is taken at a lower magnification than the others.

The size distribution of the $\mathrm{Ni}$ droplets produced was obtained using commercial image analysis software. ${ }^{19}$ Figure 2 shows the histograms of the $\mathrm{Ni}$ droplet size distributions from the films in Fig. 1. Note the statistics were improved, in some cases, by analyzing multiple images from different regions on the same film. No difference was observed, however, between different regions on the same film. The distribution of Ni droplets for the 6.5-nm-thick film is a good fit to a log normal distribution peaking at a nickel droplets size of $55 \mathrm{~nm}$. The size distributions for the other values of Ni thickness appear bi modal. By examining Fig. 1(d) the origin of these bimodal distributions can be suggested. In this figure, and to a lesser extent in Fig. 1(c), smaller droplets are seen to lie in lines extending between the larger droplets. At fluences lower than those which cause complete breakup of the films, perforation of the films is observed. The molten film around these perforations is observed to have drawn away from the center of the hole. When the density of perforations is high the retreating molten film between two holes can coalesce into filaments. The final structure becomes an array of large Downloaded 10 May 2004 to 131.227.76.10. Redistribution subject
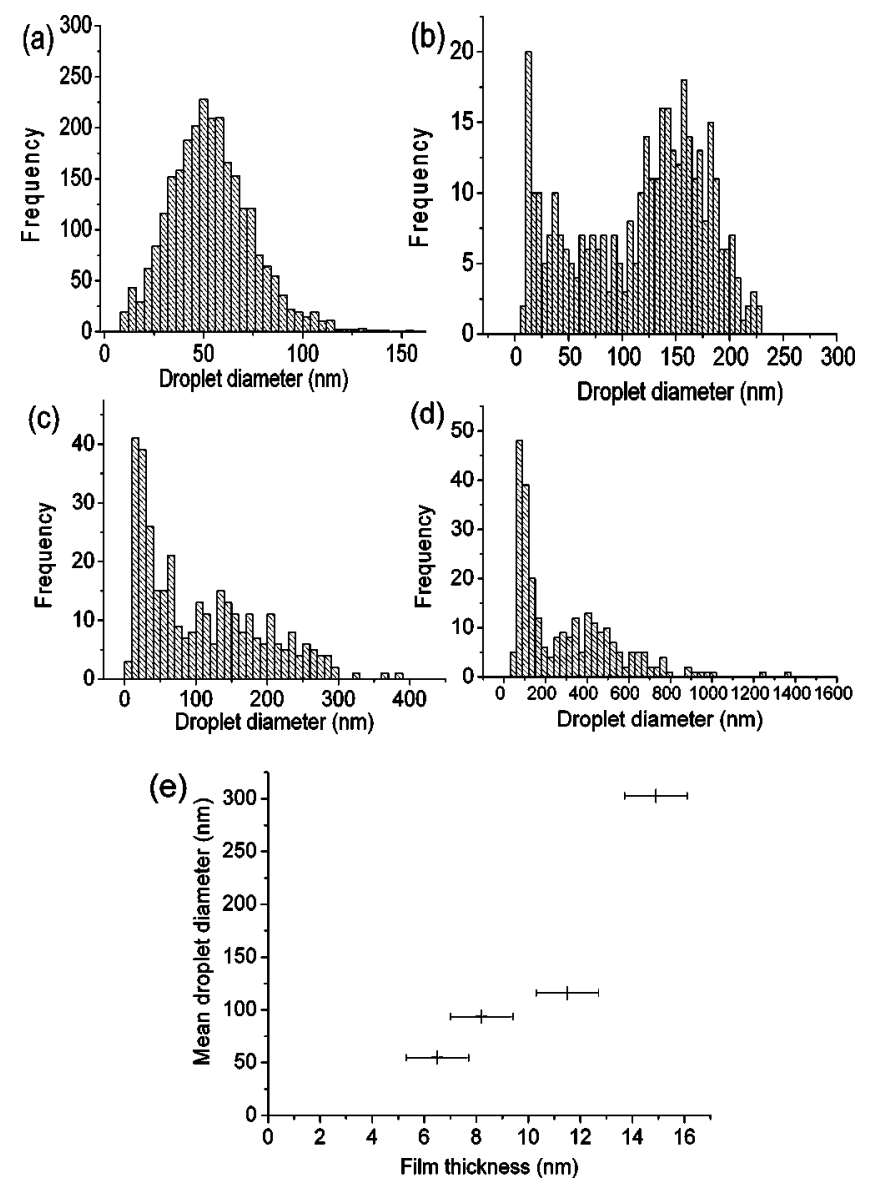

FIG. 2. (a)-(d) Histograms showing the Ni droplet diameter distributions for LN Ni thin films shown in Fig. 1. (e) Plot of the mean diameter of the Ni droplets as a function of initial film thickness.

droplets connected by a web of filaments. At slightly higher fluences these filaments will have enough energy to divide into smaller droplets, as is observed. Figure 2(e) shows a plot of the mean diameter of the $\mathrm{Ni}$ droplets as a function of initial film thickness. It can be observed that the mean droplet size increases as the initial film thickness increases, which is consistent with the thermal annealing data, of $\mathrm{Ni}$ thin films, by Chhowalla et al. ${ }^{12}$ at $700{ }^{\circ} \mathrm{C}$. Thus, choosing an appropriate film thickness can be used to control the size distribution of the nickel islands.

A selection of the processed films was used as substrates for the growth of CNTs by PECVD. The growth conditions used were a substrate temperature of $700{ }^{\circ} \mathrm{C}$, a pressure of 10 Torr (5\% acetylene, remainder nitrogen) and a growth time of $10 \mathrm{~min}$ at a bias of $-450 \mathrm{~V}$. Figure 3 shows a crosssectional SEM image of one of these samples after growth on the thinner of the two thermal oxide substrates. From Fig. 3 it is observed that the CNTs produced are split into two groups. One group is significantly longer and wider than the other, with diameters approximately the same as the Ni droplet size that was on the processed film, as has been observed elsewhere. ${ }^{14}$ The Ni droplets can be observed at the end of these tubes, as black dots in the SEM image. The CNTs in the second set appear as an "undergrowth" and are much shorter with smaller diameters than the first set. No Ni droplets were observed at the top of these CNTs but this may just be a consequence of the limited spatial resolution of the SEM, compared to the size of these tubes. Figure 4 shows an to AIP license or copyright, see http://apl.aip.org/apl/copyright.jsp 


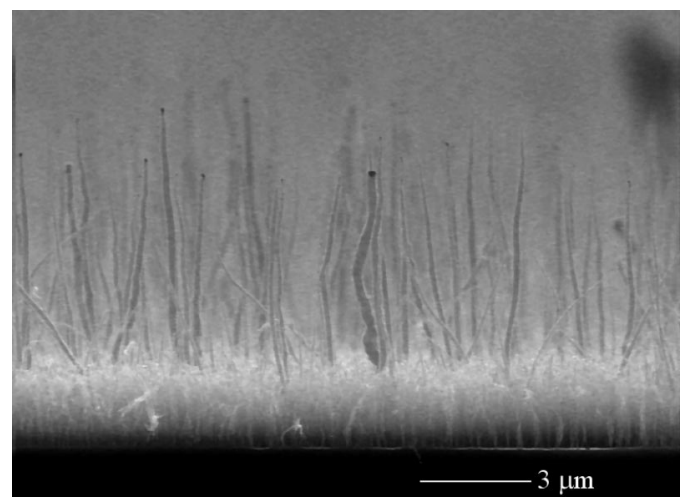

FIG. 3. Carbon nanotube grown by PECVD at $700{ }^{\circ} \mathrm{C}$ on a $\mathrm{LN} \mathrm{Ni}$ thin film on $235 \mathrm{~nm} \mathrm{SiO}{ }_{2} / \mathrm{Si}$ substrate.

AFM image of the region between the Ni droplets for the $\mathrm{LN}$ film shown in Fig. 1(d). Smaller Ni droplets can be seen covering the areas between the larger droplets. In this case the droplets are approximately $10 \mathrm{~nm}$ high. It is suggested that this second set of CNTs grow from these smaller catalyst particles. The separation between the larger CNTs is greater than is typically observed for CNTs grown on thermally annealed Ni catalyst films. This would make this technique useful for the preparation of field emission displays, as the

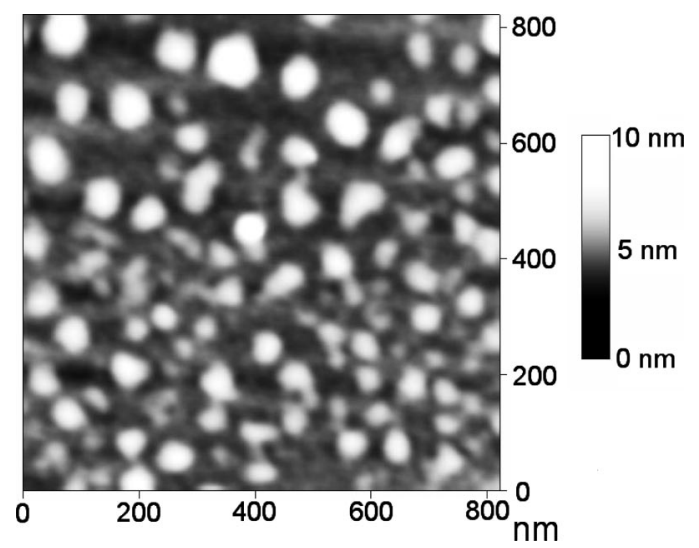

FIG. 4. AFM image of the region between the Ni droplets for the LN film shown in Fig. 1(d).
CNTs would be subject to less field screening from surrounding tubes. ${ }^{20}$

In conclusion, it has been shown that the combination of excimer laser growth and nanostructuring of thin metal films is a useful method for the preparation of large area substrates for CNT growth with well-defined, discrete, nano-scale catalyst particles. These substrates are prepared without any macroscopic heating of the substrate and have particle separations more suitable for the production of field emission cathodes.

The authors would like to thank the EPSRC Portfolio Grant and the CBE Program for funding the project.

${ }^{1}$ S. Iijima, Nature (London) 354, 56 (1991).

${ }^{2}$ S. Iijima and T. Ichihara, Nature (London) 363, 603 (1993).

${ }^{3}$ A. G. Rinzler, J. H. Hafner, P. Nikolaev, L. Lou, S. G. Kim, D. Tomanek, P. Nordlander, D. T. Colbert, and R. E. Smalley, Science 269, 150 (1995).

${ }^{4}$ W. A. D. Heer, C. Chatelain, and D. Ugarte, Science 270, 1179 (1995).

${ }^{5}$ Z. Yao, H. W. C. Postma, L. Balents, and C. Dekker, Nature (London) 402, 273 (1999).

${ }^{6}$ Y. Ye, C. C. Ahn, C. Witham, B. Fultz, J. Liu, A. G. Rinzler, D. Colbert, K. A. Smith, and R. E. Smalley, Appl. Phys. Lett. 74, 2307 (1999).

${ }^{7}$ A. Thess, R. Lee, P. Nikolaev, H. J. Dai, P. Petit, J. Robertand, C. H. Xu, Y. H. Lee, S. G. Kim, A. G. Rinzler, D. T. Colbert, G. E. Scuseria, D. Tomanek, J. E. Fischer, and R. E. Smalley, Science 273, 5274 (1996).

${ }^{8}$ T. W. Ebbesen and P. M. Ajaya, Nature (London) 358, 220 (1992).

${ }^{9}$ Z. F. Ren, Z. P. Huang, J. W. Xu, J. H. Wang, P. Bush, P. Siegal, and P. N. Provencio, Science 282, 1105 (1998).

${ }^{10}$ J. Kong, A. M. Cassell, and H. Dai, Chem. Phys. Lett. 292, 567 (1988).

${ }^{11}$ S. B. Sinnott, R. Andrews, D. Qian, A. M. Rao, Z. Mao, E. C. Dickey, and F. Derbyshire, Chem. Phys. Lett. 315, 25 (1999).

${ }^{12}$ M. Chhowalla, K. B. K. Teo, C. Ducati, N. L. Rupesinghe, G. A. J. Amaratunga, A. C. Ferrari, D. Roy, J. Robertson, and W. I. M. Milne, J. Appl. Phys. 90, 5308 (2001).

${ }^{13}$ J. D. Carey, L. L. Ong, and S. R. P. Silva, Nanotechnology 14, 1223 (2003).

${ }^{14}$ E. F. Kukovitsky, S. G. L'vov, N. A. Sainov, V. A. Shustov, and L. A. Chernozatenskii, Chem. Phys. Lett. 355, 497 (2002).

${ }^{15}$ Y. S. Ning, X. B. Zhang, Y. W. Wang, Y. L. Sun, L. H. Shen, X. F. Yang, and G. V. Tendeloo, Chem. Phys. Lett. 366, 555 (2002).

${ }^{16}$ M. N. R. Ashfold, F. Claessyens, G. Fuge, and S. J. Henley, Chem. Soc. Rev. 33, 23 (2004).

${ }^{17}$ B. O. Boskovic, V. Stolojan, R. U. A. Khan, S. Haq, and S. R. P. Silva, Nat. Mater.1, 165 (2002).

${ }^{18}$ WebElements, www.webelements.com.

${ }^{19}$ Scion Image, www.scioncorp.com.

${ }^{20}$ C. H. Poa, S. R. P. Silva, P. C. P. Watts, W. K. Hsu, H. W. Kroto, and D. R. M. Walton, Appl. Phys. Lett. 80, 3189 (2002). 